\title{
A Novel Visible-Light Photodetector Based on Chlorophyll-Modified ZnO Nanoparticles
}

\author{
Akhiruddin Maddu, ${ }^{* 1}$ Sugianto Arjo, ${ }^{2}$ and Irmansyah Sofian ${ }^{1}$ \\ ${ }^{1}$ Biophysics Division, Department of Physics, Bogor Agricultural University, Bogor 16680, Indonesia \\ ${ }^{2}$ Program Studi Pendidikan Fisika, Fakultas Keguruan dan Ilmu Pendidikan, Universitas HAMKA, Jl. Tanah \\ Merdeka, Pasar Rebo, Jakarta Timur, Jakarta 13830, Indonesia
}

Received June 20, 2016; accepted September 06, 2016; published September 30, 2016

\begin{abstract}
This paper reports a new material for visible-light detection based on chlorophyll-modified $\mathrm{ZnO}$ nanoparticles. $\mathrm{ZnO}$ nanoparticles were synthesized via a hydrothermal process. Chlorophyll was extracted from Katuk (Sauropus androgynus) leaves, an Indonesian vegetable which has many benefits for health. $\mathrm{ZnO}$ nanopartcles were mixed with the extracted chlorophyll, later to be formed into a film onto ITO coated glass substrate by the casting method. The hybrid chlorophyll-modified $\mathrm{ZnO}$ nanoparticle film was characterized for its optical absorption and current-voltage (I-V) property. A visible-light response of the hybrid chlorophyll-modified $\mathrm{ZnO}$ nanoparticle film can be seen on the I-V curves as well as a dynamic response.
\end{abstract}

$\mathrm{ZnO}$ is well known as an n-type semiconductor material with a wide band gap of $3.37 \mathrm{eV}$, associated with an absorption characteristic in the UV range [1]. So much so that $\mathrm{ZnO}$ was often used as a UV detector [2], and in a variety of other applications (UV activated $\mathrm{ZnO}$ ) such as gas sensor [3], in dye sensitized solar cells [4] and in photocatalytic degradation of dyes in wastewater [5]. Various attempts have been made to improve the characteristics of $\mathrm{ZnO}$ in sensor aplications by doping [6].

On the other hand, it has been known that the chlorophyll is the green pigment that is partly responsible for the process of photosynthesis in plants. Some studies use chlorophyll as an active component in a hybrid organic-inorganic solar cell [7].

The purpose of this research is expanding the range of applications of $\mathrm{ZnO}$ as a light detector, which in essence is a UV detector, to be a visible-light spectrum photodetector. Therefore the $\mathrm{ZnO}$ nanoparticle was modified with chlorophyll so that it might be sensitive to visible light. So far no one has done the modification of $\mathrm{ZnO}$ with chlorophyll for visible light sensor applications.

$\mathrm{ZnO}$ nanoparticles were synthesized by the hydrothermal method using zinc acetate dihydrate dissolved in ethanol solution with the addition of ethylene glycol [8]. The solution was poured into a stainless steel autoclave and then treated hydrothermally at a temperature of $150^{\circ} \mathrm{C}$ for 6 hours, being stirred at a speed of $400 \mathrm{rpm}$. The precipitate resulting from the

*E-mail: akhiruddin@ipb.ac.id; maddu3@gmail.com hydrothermal process was washed 3 times with ethanol and then dried on a hotplate at a temperature of $100^{\circ} \mathrm{C}$, subsequently calcined at $300^{\circ} \mathrm{C}$ in a furnace for 1 hour. The $\mathrm{ZnO}$ powder was analyzed by $\mathrm{X}$-ray diffraction (XRD) with a scanning electron microscope (SEM) to investigate its structure and morphology.

Chlorophyll is obtained from Katuk (Sauropus androgynus) leaves that have been extracted by using an organic solvent of $96 \%$ ethanol. The solution was filtered to obtain filtrate extract chlorophyll. To improve the stability of chlorophyll, the chlorophyll core of $\mathrm{Mg}$ is replaced by zinc $(\mathrm{Zn})$. Firstly, degradation was performed by adding a solution of chlorophyll with $1 \mathrm{M} \mathrm{HCl}$ dropwise until $\mathrm{pH} 4$ was reached while stirring with a magnetic stirrer at a speed of 400rpm. The result of this substitution is called Zn-pheophytin [9]. Furthermore, $\mathrm{Zn}^{2+}$ ions were added by dissolving $0.1 \mathrm{gml}^{-1}$ zinc acetate dihydrate with ethanol while stirring for 30 minutes until the color changed. After the reaction, the mixture was frozen in a freezer $\left(-20^{\circ} \mathrm{C}\right)$ overnight, then its optical absorption was measured. Zn- pheophytin solution was dried using a freeze dryer.

Hybrid chlorophyll-modified $\mathrm{ZnO}$ nanoparticles were coated on an ITO coated glass substrate by the casting method from a mixture of $\mathrm{ZnO}$ nanoparticles and $\mathrm{Zn}$ substituted chlorophyll. The hybrid organic-inorganic nanoparticle film was measured for its optical characteristics by a UV-Vis spectrophotometer. Then, the film of a hybrid chlorophyll-ZnO nanoparticle was sandwhiched between two ITO-coated glass substrates, and then its response to visible light was measured by taking current-voltage (I-V) data and dynamic response of a visible-light sensor.

Figure 1 shows the X-ray diffraction pattern of the sample of $\mathrm{ZnO}$ nanoparticles prepared by the hydrothermal method. The diffraction pattern showed excellent crystallinity of $\mathrm{ZnO}$, as seen by very clear and sharp diffraction peaks. Based on the peaks in the diffraction pattern, a hexagonal wurtzite structure of $\mathrm{ZnO}$ can easily be indicated according to JCPDS No. 36-145 [10]. The entire peak of $\mathrm{ZnO}$ appears in the diffraction 
pattern as extending from the angle of $2 \theta=30^{\circ}-70^{\circ}$, consecutive to the reflection planes of $\left(\begin{array}{lll}1 & 0 & 0\end{array}\right),\left(\begin{array}{lll}0 & 0 & 2\end{array}\right),\left(\begin{array}{ll}1 & 0\end{array}\right.$

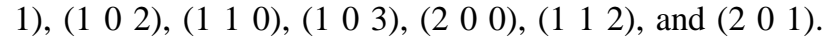
The sample formed was crystalline $\mathrm{ZnO}$ with a hexagonal wurtzite structure [11].

The average crystal size (ACS) was calculated based on the widening of the spectrum of diffraction using the following Debye-Scherrer relationship,

$$
\sigma=\frac{0.94 \lambda}{\beta \cos \theta},
$$

where $\sigma$ is the crystallite size, $\lambda=1.5604 \AA$ is the wavelength of X-ray using a $\mathrm{Cu} \mathrm{K}_{\alpha}$ source, $\beta$ - the fullwidth at half-maximum (FWHM) of the diffraction peak, and $\theta$ - the diffraction angle. The diffraction pattern looks slightly widened indicating the small size of $\mathrm{ZnO}$ crystals. The calculations were made using the Scherrer equation, the obtained average crystal size of $\mathrm{ZnO}$ was about $50 \mathrm{~nm}$, which is shown by $\mathrm{ZnO}$ nanostructures.

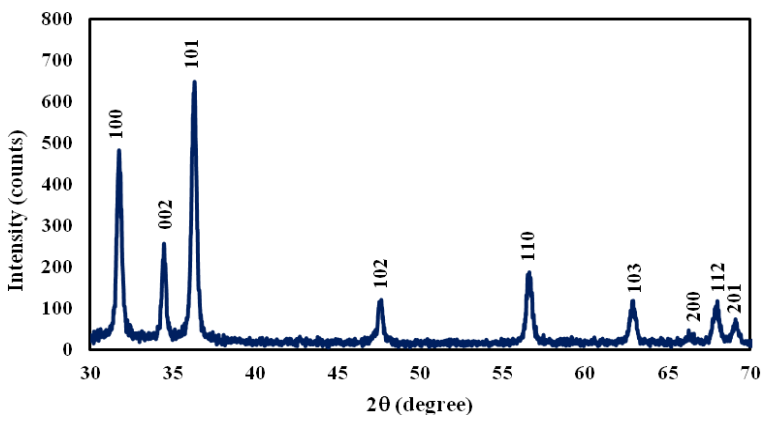

Fig.1. XRD pattern of $\mathrm{ZnO}$ nanoparticles.

The surface morphology of $\mathrm{ZnO}$ nanoparticles is shown in Fig. 2. ZnO particles clearly look relatively uniform in size and shape, which can be seen by clearly separated granules. By using a scale ruler in the image, we can estimate that the average size of the particles is about $100 \mathrm{~nm}$.

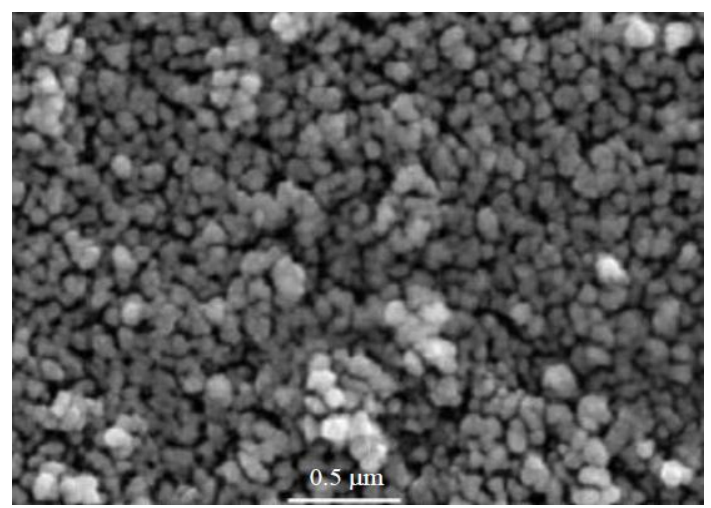

Fig. 2. SEM photograph of $\mathrm{ZnO}$ nanoparticles.

Figure 3 shows the absorbance spectra of a $\mathrm{ZnO}$ film and hybrid chlorophyll-modified $\mathrm{ZnO}$ nanoparticle film in the range of the $\mathrm{UV}-\mathrm{Visible}$ region. It seems that the $\mathrm{ZnO}$ film without chloropyll modification has strong absorption in the UV region with the absorption edge at around $380 \mathrm{~nm}$, which corresponds to the wide bandgap energy of $\mathrm{ZnO}(3.37 \mathrm{eV})$. While the hybrid chlorophyll-modified $\mathrm{ZnO}$ film has an absorption characteristic in the visible light range, the absorption band around the blue and red spectrum are characteristics of chlorophyll absorption.

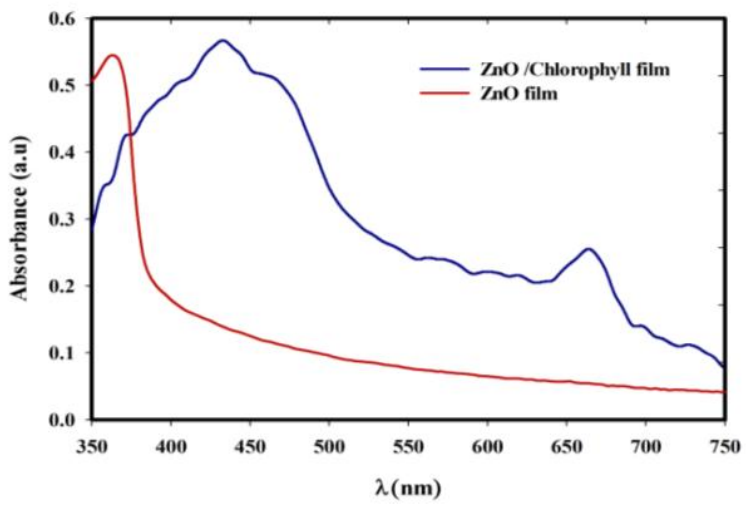

Fig. 3. Absorbance of $\mathrm{ZnO}$ film and hybrid $\mathrm{ZnO} / \mathrm{Chlorophyll} \mathrm{film}$

Figure 4 shows the current-voltage (I-V) characteristics of the hybrid chlorophyll-modified $\mathrm{ZnO}$ nanoparticles film in the dark and under an illuminated condition, the data was taken using a I-V meter (Keithley 2400 Sourcemeter). The I-V characteristic shows the rectification behavior (diode characteristics). In a dark condition, the I-V curve shows that the knee voltage is large enough around $1.7 \mathrm{~V}$. When the hybrid organicinorganic nanoparticle film is irradiated by visible light, the current increased rapidly, the resulting I-V curve is very different compared to the dark condition, the knee voltage shifted close to zero.

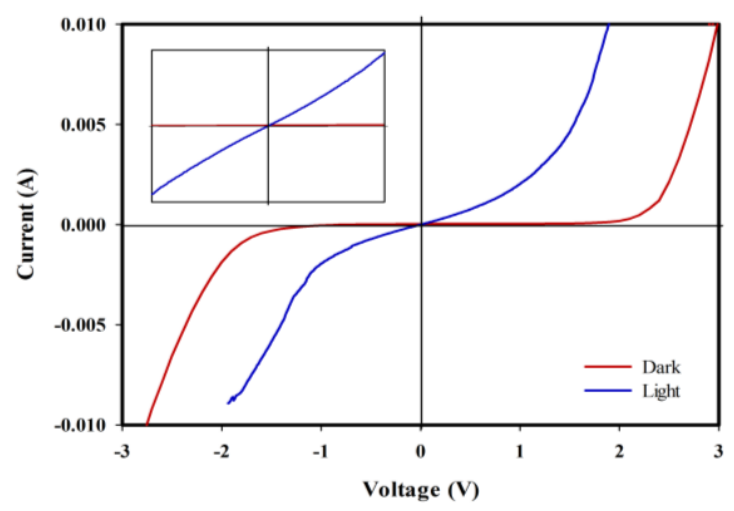

Fig. 4. I-V characteristics of hybrid $\mathrm{ZnO} /$ Chlorophyll film. Inset: linear part of I-V curve.

Based on the I-V curve it was also found that the resistance value of the hybrid chlorophyll-modified $\mathrm{ZnO}$ nanoparticle film decreased when irradiated, as indicated 
by the slope of the curve $(\Delta \mathrm{I} / \Delta \mathrm{V})$. As shown in the inset in Fig. 4 , the slope of the I-V curves is very different in the dark and irradiated conditions, the slope of the I-V curve in a irradiated condition is greater, which indicates that the resistance value is smaller. In this case chlorophyll is responsible for the response to visible light, in which electrons excited by photons of visible light on chlorophyll transferred easily in the hybrid chlorophyll modified $\mathrm{ZnO}$ nanoparticle.

The measurement of dynamic response of visible-light sensor based on hybrid chlorophyll-modified $\mathrm{ZnO}$ nanoparticle film is made using a voltage divider circuit, namely by connecting in series the hybrid organicinorganic nanoparticle film with a fixed resistor $\left(\mathrm{R}_{\mathrm{L}}\right)$ (Fig. $5)$. The voltage source is connected in series in the circuit, and the voltage sensor (PASCO) connected to the ends of the hybrid organic-inorganic nanoparticle film as an active material in visible light.

The principle of this sensor is that the resistance value of the hybrid chlorophyll-modified $\mathrm{ZnO}$ nanoparticle film will change when irradiated due to an increase in the free charge induced by visible light. This free charge contributes to a change of resistance of the hybrid organic-inorganic film. The measurement of a dynamic response is made by measuring voltage at the ends of the hybrid film, first before irradiation then followed by irradiation with a visible light lamp $(\mathrm{ON})$, maintained for a while, after which the light source is turned off (OFF). The data were taken using a computer (with DataStudio Software, PASCO) which is connected to the voltage sensor via Interface (ScienceWorkshop 750, PASCO). This process is performed a total of four cycles simultaneously.

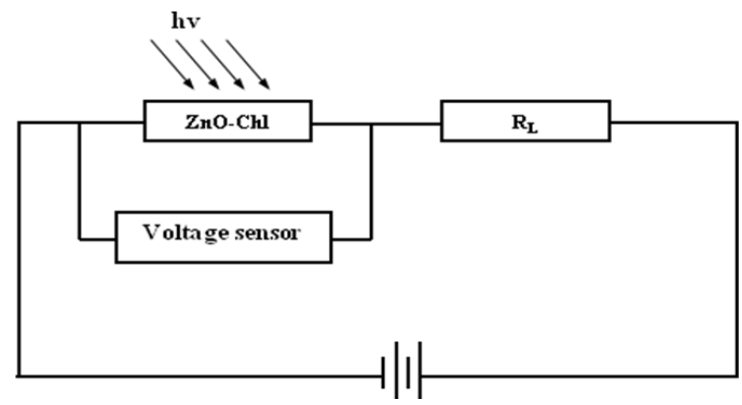

Fig.5. The measurement cricuit of dynamic response of a visible light sensor based on a hybrid chlorophyll- $\mathrm{ZnO}$ film.

Figure 6 shows the curve of dynamic response of a visible light sensor based on a hybrid chlorophyllmodified $\mathrm{ZnO}$ nanoparticle film. Before irradiation (dark condition), the voltage on the voltmeter is $0.02 \mathrm{~V}$, shortly after irradiation with visible light (light condition) the voltage quickly increases 5 times $(0.1 \mathrm{~V})$ as compared to no irradiation (dark), the response time is quite short. When the light source is turned off (OFF), the voltage drops rapidly and achieves its original voltage value, although the recovery time is slower than the response time.

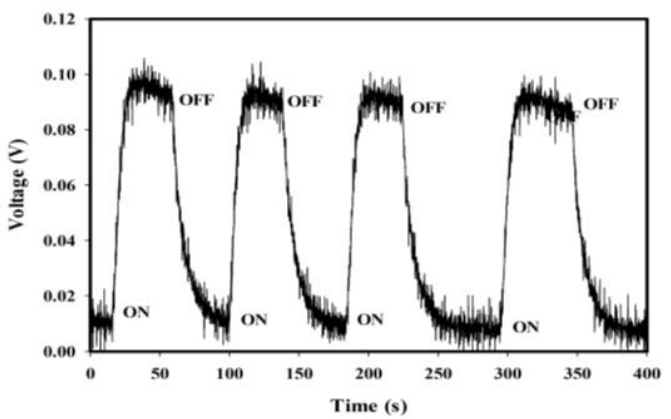

Fig. 6. Dynamic response of a visible-light photodetector based on a hybrid $\mathrm{ZnO}-$ Chlorophyll film.

The increase in voltage under irradiation is due to reduced electrical resistance of an active material in the visible light of a hybrid chlorophyll-modified $\mathrm{ZnO}$ nanoparticle film. Because the active layer of the hybrid organic-inorganic nanoparticle film is connected in a voltage divider circuit with a fixed resistor $\left(\mathrm{R}_{\mathrm{L}}\right)$ and a voltage source, the voltage source will be divided in two resistance components, namely a fixed resistor $\left(R_{L}\right)$ and hybrid film. When one of the components changes its resistance value, rationing the voltage value will change. When irradiated, the resistance value of the hybrid organic-inorganic nanoparticle film decreased and the voltage at its ends increased.

In conclusion, the modification of a $\mathrm{ZnO}$ nanoparticle with Zn-substituted chlorophyll siginficantly changes the response of a hybrid film to visible light. The dynamic response shows that the hybrid $\mathrm{ZnO}$-chlorophyll film has a very quick response to visible light, and so it could potentially be used as a visible light sensor.

\section{References}

[1] D.J. Sornalatha, S. Bhuvaneswari, S. Murugesan, P. Murugakoothan, Optik 126, 63 (2015).

[2] K.L. Foo, M. Kashif, U. Hashim, M.E. Ali, Optik 124, 5373 (2013).

[3] M. Procek, T. Pustelny, Phot. Lett. Poland 7, 50 (2015).

[4] J. A. Anta, E. Guillén, R. Tena-Zaera, J. Phys. Chem. C 116, 11413 (2012).

[5] V. Sanna, N. Pala, V. Alzari, D. Nuvoli, M. Carcelli, Mat. Lett. 162, 257 (2016).

[6] C.O. Chey, X. Liu, H. Alnoor, O. Nur, M. Willander, Phys. Status Solidi RRL 9(1), 87 (2015).

[7] A. Kondapi, Int. J. Nanoparticles 7(3/4), 307 (2014).

[8] S. Ashoka, G. Nagaraju, C.N. Tharamani, G.T. Chandrappa, Mat. Lett. 63, 873 (2009).

[9] J.B. Zvezdanovic, D.Z. Markovic, S.M. Milenkovic, J. Serb. Chem. Soc. 71(2), 187 (2012).

[10] X. Lian, Y. Li, D. An, Y. Zou, Q. Wang, N. Zhang, Mat. SciencePoland 32(3), 514 (2014).

[11] S. Wein, J. Zhao,W. Du, Ceramics Internat. 41, 769 (2015). 